\title{
The Release of Leukotrienes in the Respiratory Tract during Infection with Respiratory Syncytial Virus: Role in Obstructive Airway Disease
}

\author{
BENJAMIN VOLOVITZ, ROBERT C. WELLIVER, GIOVANNA DE CASTRO, DEBORAH A. \\ KRYSTOFIK, AND PEARAY L. OGRA \\ Departments of Pediatrics [B.V., R.C.W., P.L.O.] and Microbiology [P.L.O.], State University of New York at \\ Buffalo, and Division of Infectious Diseases [B.V., R.C.W., G.D.C., D.A.K., P.L.O.] Children's Hospital, Buffalo \\ New York 14222
}

\begin{abstract}
Samples of nasopharyngeal secretions from a group of 73 infants with bronchiolitis or upper respiratory illness alone during infection with respiratory syncytial virus were analyzed for leukotriene $\mathrm{C}_{4}\left(\mathrm{LTC}_{4}\right)$ content using a reverse-phase high-pressure liquid chromatography assay with confirmation by radioimmunoassay. Titers of respiratory syncytial virus (RSV)-specific IgE in nasopharyngeal secretion (NPS) specimens were determined using an enzyme-linked immunosorbent assay. The highest concentrations of $\mathrm{LTC}_{4}$ were found in the first 3 to 8 days after the onset of illness, and $\mathrm{LTC}_{4}$ was detectable in progressively lower concentrations in samples obtained up to 28 days after the onset of illness. LTC $_{4}$ was detected in samples of NPS obtained in the acute phase of illness from $67 \%$ of infants with bronchiolitis due to RSV and in $33 \%$ of samples of NPS obtained during the same interval from infants with upper respiratory illness alone $(p<0.025)$. Concentrations of $\mathrm{LTC}_{4}$ in children with bronchiolitis were 5 -fold higher $(1271 \mathrm{pg} / \mathrm{ml})$ than the mean concentration of $\mathrm{LTC}_{4}$ in children with upper respiratory illness $(224 \mathrm{pg} /$ $\mathrm{ml}, p<0.02$ ). $\mathrm{LTC}_{4}$ was detected in $83 \%$ of the children developing an $\mathrm{RSV}$-IgE response and in $24 \%$ of subjects not developing an RSV-IgE response $(p<0.001)$. Quantities of $\mathrm{LTC}_{4}$ measured in NPS were directly correlated with the magnitude of the RSV-IgE response in secretions $(r=0.33, p<0.02)$. These studies lend support to previous investigations suggesting that severe bronchiolitis due to RSV results from IgE-mediated hypersensitivity reactions to viral antigens, with release of chemical mediators of airway obstruction. Their implications should be considered in new approaches to therapy of RSV bronchiolitis. (Pediatr Res 24: 504-507, 1988)
\end{abstract}

\section{Abbreviations}

NPS, nasopharyngeal secretions

URI, upper respiratory illness

RSV, respiratory syncytial virus

$\mathrm{LTC}_{4}$, leukotriene $\mathrm{C}_{4}$

ELISA, enzyme-linked immunosorbent asay

PBS, phosphate-buffered saline

HPLC, high-pressure liquid chromatography

RIA, radioimmunoassay

Received April 4, 1988; accepted June 23, 1988.

Correspondence and reprint requests Robert C. Welliver, M.D., Division of Infectious Diseases, Children's Hospital of Buffalo, 219 Bryant Street, Buffalo, NY 14222.

Supported in part by grants from the National Institute of Allergy and Infectious Diseases (AI-15939) and the National Institute of Child Health and Human Development (HD-19679).
Infection with RSV is the most common cause of bronchiolitis in infancy (1). Previous studies have indicated that infants with RSV bronchiolitis exhibit increased levels of virus-specific IgE and histamine in respiratory tract secretions in comparison to individuals with URI alone due to $\operatorname{RSV}(2,3)$. In addition to histamine, other mast cell products, especially $\mathrm{LTC}_{4}$ and $\mathrm{LTD}_{4}$, have been shown to be potent mediators of bronchoconstriction and increased airway mucus secretion (4-6). However, their role in wheezing assoçiated with respiratory infection in infancy has not been determined. Bronchoactive and vasoactive mediators may also be released by other effector cells that are present in the respiratory tract during acute viral infection $(7,8)$. Our study was designed to determine the presence of LT in the nasopharyngeal mucosa during RSV infection and to evaluate their potential role in RSV-induced wheezing in infancy and childhood.

\section{MATERIALS AND METHODS}

Subjects. A total of 73 children with RSV infection hospitalized during the winters of 1986 and 1987 was enrolled in this study. A diagnosis of bronchiolitis with or without pneumonia was made in 48 children on the basis of physical examination by a single member of the study team and a careful review of radiographs with a radiologist. The other 25 subjects had URI alone without wheezing. The subjects included 56 infants less than 1 yr of age ( 38 with bronchiolitis, 18 with URI) and 17 children from 1 to $6 \mathrm{yr}$ of age ( 10 with bronchiolitis, seven with URI). Assays for $\mathrm{LTC}_{4}$ were carried out by an individual who had no knowledge of the clinical diagnosis.

Sample collection. After explanation of the goals and risks of the study and obtaining of signed statements of informed consent, samples of NPS were collected for identification of RSV infection for determination of the RSV-specific IgE antibody titer, as well as for determination of $\mathrm{LTC}_{4}$ content. Samples were obtained by direct aspiration into polyethylene catheters passed into the nasopharynx (9). Infection with RSV was confirmed in one aliquot of secretions by indirect immunofluorescence assays as previously described (9). The sensitivity and specificity of this assay are in excess of $92 \%$. The supernatant of this specimen was used to determine the magnitude of the RSV-IgE response. Measured titers of RSV-IgE were standardized to a protein content of $1 \mathrm{mg} / \mathrm{ml}$ of fluid (2). An additional aliquot of secretions (subsequently measured to be between 0.3 and $0.5 \mathrm{ml}$ in all cases) was obtained for $\mathrm{LTC}_{4}$ determination also by direct aspiration into a polyethylene catheter and rinsing with $0.5 \mathrm{ml}$ of PBS prepared with HPLC-grade water (Aldrich, Milwaukee, WI). Samples for determination of $\mathrm{LTC}_{4}$ content were trans- 
ported on ice to the laboratory and stored at $-70^{\circ} \mathrm{C}$. Measured concentrations of $\mathrm{LTC}_{4}$ were standardized to $0.1-\mathrm{ml}$ volumes of secretion.

A total of two to four wk after the onset of acute illness, the subjects were reevaluated and a second sample of secretions was obtained. A small number of infants with documented RSV infection could not be studied for $\mathrm{LTC}_{4}$ content at the time of acute illness but were tested during convalescence. Thus, 64 infants were studied during the acute phase of illness, and 17 of these returned to have a convalescent sample obtained. An additional nine subjects were studied only during the convalescent period.

$R S V$-IgE assay. Titers of RSV-specific IgE were measured by an ELISA previously described (2). In brief, RSV grown in the laboratory was purified and concentrated by sucrose-gradient centrifugation. Uninfected tissue culture cells were similarly processed for use as a control. The virus or control preparations $(0.1 \mathrm{ml})$ were fixed overnight to the bottom of wells of polyvinyl micro-ELISA plates (Dynatech Laboratories, Alexandria, VA) after dilution to $1: 100$ in carbonate buffer ( $\mathrm{pH} 9.6$ ). On the next morning the plates were washed three times with a washing solution consisting of PBS and $0.05 \%$ Tween 20 (Fisher Scientific, Fairlawn, NJ). Test wells were then incubated with $0.1 \mathrm{ml}$ of serial 2-fold dilutions of secretions in PBS. After $2 \mathrm{~h}$ of incubation at $37^{\circ} \mathrm{C}$, the plates were washed and incubated for 2 more $h$ with $0.1 \mathrm{ml}$ of horseradish peroxidase-conjugated goat anti-human IgE (Miles Laboratories, Elkhart, IN) diluted 1:00 in PBS and Tween 20, with $1.5 \%$ fetal-calf serum added. After another washing, $0.1 \mathrm{ml}$ of O-phenylenediamine (Sigma Chemical, St. Louis, MO) in an $0.08 \%$ solution in PBS, with $10 \mu \mathrm{l}$ of hydrogen peroxidase added, was incubated in wells for $30 \mathrm{~min}$. End-points were determined by spectrophotometer at $488 \mathrm{~nm}$. Positive readings (indicating the presence of RSV-IgE) were those in which the optical density in wells coated with RSV was more than twice that in wells coated with similarly processed uninfected cell preparations. Known positive assays could be blocked by incubation of the goat anti-IgE with purified human IgE but not human IgA, IgG, or light chains. Positive assays could also be blocked by incubation of secretions with RSV-infected tissue culture cells followed by centrifugation but not by incubation with uninfected tissue culture cells (2).

Measurement of leukotrienes. The NPS samples were initially centrifuged at $1500 \times \mathrm{g}$ in $4^{\circ} \mathrm{C}$ for $20 \mathrm{~min}$. A $0.1-\mathrm{ml}$ volume of the supernatant, containing secretion in PBS, was mixed with 4 vol of ethanol, incubated for $2 \mathrm{~h}$ on ice, and centrifuged as before. The supernatant was vacuum extracted to dryness in a rotary evaporator and the residue obtained was subsequently dissolved in $20 \%$ methanol and applied to a Sep-Pak $\mathrm{C}_{18}$ cartridge (Millipore Waters Associates, Millford, MA) activated with 10 $\mathrm{ml}$ of methanol. The sample thus prepared was subjected to vacuum extraction to dryness and the residue redissolved in 500 $\mu \mathrm{l}$ of $30 \%$ methanol. A total of $5 \mathrm{ng}$ of purified prostaglandin $\mathrm{B}_{2}$ (Sigma Chemical Co., St. Louis, MO) was introduced into the sample as an internal standard. The sample was then injected into a $\mathrm{C}_{18}$ reverse-phase column (Beckman, San Ramon, CA) and eluted isocratically in an HPLC system (Pharmacia, Piscataway, $\mathrm{NJ}$ ) with a mixture of $80 \%$ methanol, $20 \%$ water, $0.05 \%$ trifluoroacetic acid, and $0.5 \%$ triethylamine (Pierce, Rockford, IL). Each sample was tested in duplicate. Purified preparations of $\mathrm{LTC}_{4}$ (generously given by J. Rokach, Merck Frost, Montreal, Quebec, Canada) were used as standards and tested in parallel with the sample. Recovery of $\mathrm{LTC}_{4}$ was $86 \pm 7 \%$.

$R I A$ for $L T C_{4}$. The presence of $\mathrm{LTC}_{4}$ in materials determined to be positive by HPLC was verified by a specific RIA (New England Nuclear, Boston, MA). Samples collected after separation with HPLC were dried and then dissolved in an assay buffer. A tracer, containing $\left[{ }^{3} \mathrm{H}\right] \mathrm{LTC}$, was added to the samples along with specific anti-LTC 4 antibody. After incubation, absorption with charcoal suspension and centrifugation at $1500 \times g$ for 15 min, the supernatant was added to Atomlight, a scintillation solution (DuPont, Boston, MA). The radioactivity was measured in a liquid scintillation counter (Beckman LS9000, Fullerton, CA). Recovery of $\mathrm{LTC}_{4}$ from the HPLC in the RIA was $76 \pm$ $9 \%$.

Statistical methods. Differences in titers of RSV-IgE or of $\mathrm{LTC}_{4}$ content in nasopharyngeal secretions among patient groups were calculated by Student's $t$ test. Chi-square analysis was used to compare the rates of detection of RSV-IgE and $\mathrm{LTC}_{4}$ among groups. Correlation coefficients were calculated using standard methods.

\section{RESULTS}

Temporal kinetics of $L T C_{4}$ in NPS. Concentrations of $\mathrm{LTC}_{4}$ measured in secretions on different days after the onset of illness are shown in Figure 1. Maximum concentrations of $\mathrm{LTC}_{4}$ were observed from 3 to 8 days after the onset of illness. Measureable concentrations appeared to decline at 9 to 10 days after the onset of illness and persisted in low levels in some individuals up to 28 days after the onset of illness but not beyond.

Relationship of $\mathrm{LTC}_{4}$ content in NPS to form of illness. Concentrations (mean $\pm \mathrm{SD}$ ) of leukotriene measured in samples of NPS from patients with different forms of illness due to RSV are shown in Table 1. During the acute phase of illness, LTC $_{4}$ was detectable in 29 of $43(67 \%)$ infants with bronchiolitis but in only seven of 21 (33\%) infants with upper respiratory illness alone $(p<0.025)$. Mean concentrations of $\mathrm{LTC}_{4}$ were more than 5 -fold higher in infants with bronchiolitis due to RSV than in infants with URI alone $(p<0.02)$. LTC $_{4}$ was detectable in low concentrations in approximately $25 \%$ of subjects studied in the convalescent period, with no difference in frequency of detection in the two illness groups.

Relationship of $R S V$-IgE response to presence of $L T C_{4}$. The relationship of the development of an IgE antibody response to RSV with the release of $\mathrm{LTC}_{4}$ in NPS is illustrated in Table 2. Samples for determination of RSV-IgE titers were available from 64 subjects. $\mathrm{LTC}_{4}$ was detectable in secretions of 24 of $29(83 \%)$ individuals developing an RSV-IgE response but in only 10 of $35(29 \%)$ individuals not developing a detectable RSV-IgE response $(p<0.001)$.

The mean concentration of $\mathrm{LTC}_{4}$ detected in samples of NPS from children with positive RSV-IgE responses was $736 \pm 680$

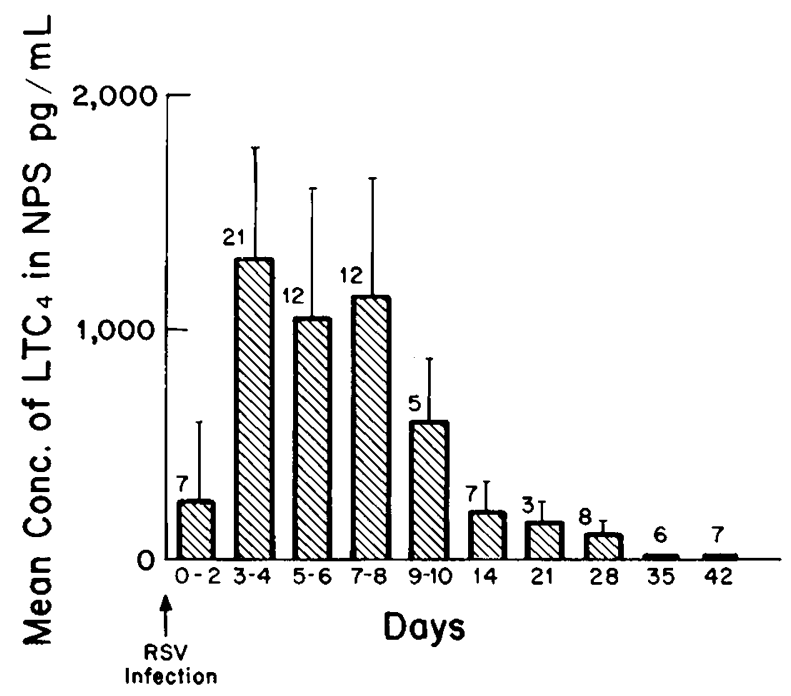

Fig. 1. Concentration of $\mathrm{LTC}_{4}$ in samples of nasopharyngeal secretions obtained from patients with RSV infection. Hatched bars indicate mean; intervals indicate ISD; and figures over bars indicate number of subjects studied at each interval. Horizontal axis refers to days after the onset of symptoms of respiratory illness. 
Table 1. Presence of $\mathrm{LTC}_{4}$ in nasopharyngeal secretions of infants and children with RSV infection

\begin{tabular}{ccccc}
\hline $\begin{array}{c}\text { Diagnostic } \\
\text { group }\end{array}$ & $\begin{array}{c}\text { Days after } \\
\text { onset of } \\
\text { illness }\end{array}$ & $\begin{array}{c}\text { No. } \\
\text { studied }\end{array}$ & $\begin{array}{c}\text { No. (\%) } \\
\text { with LTC } 4\end{array}$ & $\begin{array}{c}\text { Group mean LTC } \\
\text { concentration (pg/ } \\
0.1 \mathrm{ml})\end{array}$ \\
\hline Bronchiolitis & $0-7$ & 43 & $29(67)^{*}$ & $1271 \pm 239 \dagger$ \\
URI alone & $14-42$ & 18 & $5(28)$ & $139 \pm 52$ \\
& $0-7$ & 21 & $7(33)^{*}$ & $224 \pm 114 \dagger$ \\
& $14-42$ & 8 & $2(25)$ & $125 \pm 77$ \\
\hline
\end{tabular}

$*_{p}<0.025$.

$\dagger p<0.02$.

Table 2. Relationship of development of $R S V-I g E$ response to presence of $L T C_{4}$ in respiratory secretions

\begin{tabular}{|c|c|c|c|c|}
\hline \multirow{3}{*}{$\begin{array}{l}\text { RSV-IgE } \\
\text { response }\end{array}$} & \multicolumn{4}{|c|}{$\mathrm{LTC}_{4}$ in NPS } \\
\hline & \multicolumn{2}{|c|}{ Present } & \multicolumn{2}{|c|}{ Absent } \\
\hline & $n$ & $\%$ & $n$ & $\%$ \\
\hline \multicolumn{4}{|l|}{ Positive } & 17 \\
\hline \multicolumn{5}{|l|}{ Negative } \\
\hline$n=35$ & $10^{\circ}$ & $29^{*}$ & 25 & 71 \\
\hline Total 64 & 34 & & 30 & \\
\hline
\end{tabular}

${ }^{*} p<0.001$.

$\mathrm{pg} / 0.1 \mathrm{ml}$, which was significantly higher than the mean concentration of $\mathrm{LTC}_{4}$ in subjects without a detectable RSV-IgE response $(202 \pm 331 \mathrm{pg} / 0.1 \mathrm{ml}, p<0.02)$. A weaker overall correlation of the magnitide of the RSV-IgE response of individual patients with the $\mathrm{LTC}_{4}$ content of NPS was noted $(r=0.33$, $\mathrm{P}<0.02$ ).

Relationship of patient age to presence of $L T C_{4}$. The relationship of the presence of an RSV-IgE response and the presence of $\mathrm{LTC}_{4}$ in patients older than or younger than 12 months of age at the time of infection is shown in Table $3 . \mathrm{LTC}_{4}$ was detected in secretions of 18 of $23(78 \%)$ RSV-IgE positive patients in the first year of life and in six of six $(100 \%, p=N S)$ individuals developing an IgE response who were older than 12 months of age at the time of infection. In a similar fashion, $27 \%$ of individuals younger than 12 months of age who did not develop an RSV-IgE response had detectable $\mathrm{LTC}_{4}$ in their secretions, whereas $12 \%$ of RSV-IgE-negative individuals older than 12 months of age at the time of infection had $\mathrm{LTC}_{4}$ present in their secretions $(P=\mathrm{NS})$. Overall, $51 \%$ of subjects younger than 12 months of age and $50 \%$ of patients more than 12 months of age at the onset of illness had detectable $\mathrm{LTC}_{4}$ in NPS, indicating that patient age was not as important factor as was the development of an RSV-IgE response in determining the quantity of $\mathrm{Ltc}_{4}$ released into secretions.

\section{DISCUSSION}

The sulfidopeptide $\mathrm{LT}\left(\mathrm{LTC}_{4}, \mathrm{LTD}_{4}\right.$, and $\left.\mathrm{LTE}_{4}\right)$ are among the major mast cell mediators responsible for the late-phase of bronchospasm in asthma (10). $\mathrm{LTC}_{4}$ and $\mathrm{LTD}_{4}$ are the most potent constrictors of smooth muscle and stimulators of airway mucus production (4-6). In addition, they increase vascular permeability and induce pulmonary edema $(4,11,12)$. Results of this study, demonstrating that concentrations of $\mathrm{LTC}_{4}$ are greater in infants with wheezing at the time of RSV infection than in infants with URI alone, suggest that the LT may play an important role in the pathogenesis of episodes of RSV-induced wheezing. Maximum release of $\mathrm{LTC}_{4}$ was observed from 3 to 8 days after the onset of symptoms of respiratory infection, the time at which airway obstruction after RSV infection is most severe. $\mathrm{LTC}_{4}$ release was also correlated with production of RSV-
Table 3. $L T C_{4}$ release in respiratory secretions analyzed by patient age at time of infection

\begin{tabular}{|c|c|c|c|}
\hline \multirow{2}{*}{$\begin{array}{c}\text { Patient } \\
\text { age } \\
(\mathrm{mo})\end{array}$} & \multicolumn{2}{|c|}{$\begin{array}{l}\text { Number with detectable } \\
\text { LTC }_{4} / \text { no. tested }\end{array}$} & \multirow[b]{2}{*}{ Total } \\
\hline & $\begin{array}{l}\text { RSV-IgE } \\
\text { positive }\end{array}$ & $\begin{array}{l}\text { RSV-IgE } \\
\text { negative }\end{array}$ & \\
\hline$<12$ & $18 / 23(78 \%)$ & $7 / 26(27 \%)$ & $25 / 49(51 \%)$ \\
\hline$>12$ & $6 / 6(100 \%)$ & $1 / 8 \quad(12 \%)$ & $7 / 14(50 \%)$ \\
\hline
\end{tabular}

specific IgE. In other studies from this laboratory (13), $\mathrm{LTC}_{4}$ has been quantitated in respiratory secretions obtained from individuals with nonrespiratory illnesses. The mean LTC content in these samples $(158 \mathrm{pg} / 0.1 \mathrm{ml})$ was similar to the LTC content of secretions obtained from patients with URI alone in the present study $(224 \mathrm{pg} / 0.1 \mathrm{ml})$. Patients with bronchiolitis due to viral agents other than RSV have not been studied extensively.

$\mathrm{LTC}_{4}$ and $\mathrm{LTD}_{4}$ are released after stimulation of human mast cells (14-16) and other human inflammatory cells $(7,8)$. A variety of inflammatory cells is present in the lung in individuals with bronchiolitis (17). An alternative hypothesis might be that release of $\mathrm{IgE}$, histamine, $\mathrm{LTC}_{4}$ and other compounds into the respiratory tract might be greater in cases of bronchiolitis than in cases of URI because of the greater inflammatory response in the lower airway in bronchiolitis. Previous studies comparing infants with RSV pneumonia without wheezing to infants with bronchiolitis have demonstrated that, despite a presumably equivalent amount of inflammation, IgE responses and histamine release are greater in the group with bronchiolitis (2). Antibody responses in other isotypes were similar in each group (18). No patients with RSV pneumonia without wheezing were available in the current investigation. Nevertheless, the results of the previous studies indicate that RSV-IgE production is unrelated to inflammation. In our study, $\mathrm{LTC}_{4}$ was detectable more often in individuals developing an RSV-IgE response than in those not developing such a response $(p<0.001)$ and was of greater magnitude in RSV-IgE responders $(p<0.02)$. A more modest correlation of $\mathrm{LTC}_{4}$ release with the absolute magnitude of the RSV-IgE responses was observed $(r=\mathrm{u} 0.33, p<0.02)$. Therefore, some $\mathrm{LTC}_{4}$ may have been released nonspecifically by inflammatory cells in the lung, but $\mathrm{LTC}_{4}$ release was apparently enhanced by RSV-IgE synthesis, which would not be related to inflammation. Overall the findings support a primary role for production of RSV-specific IgE and IgE-directed mediator release in the pathogenesis of bronchiolitis. It may be that individuals who release lower concentrations of $\mathrm{LTC}_{4}$ as a result of non-IgEmediated mechanisms develop milder forms of bronchiolitis, whereas individuals who develop an RSV-IgE response release greater quantities of $\mathrm{LTC}_{4}$ and histamine and experience more severe forms of illness.

Acknowledgment. The authors thank Paula M. Peters for her assistance in the preparation of the manuscript.

\section{REFERENCES}

1. Kim HW, Arrobio JO, Brandt CD, Jeffries BC, Pyles G, Feid JC, Chanock RM, Parrott RH 1973 Epidemiology of respiratory syncytial virus infection in Washington, DC. I. Importance of the virus in different respiratory tract disease syndromes and temporal distribution of infection. Am J Epidemiol 98:216-225

2. Welliver RC, Wong DT, Sun M, Middleton E Jr, Vaughan RS, Ogra PL 1981 The development of respiratory syncytial virus-specific IgE and release of histamine in nasopharyngeal secretions after infection. $N$ Engl $J$ Med 305:841-846

3. Bui RHD, Molinaro GA, Kettering JD, Heiner DC, Imagawa DT, St. Geme $\mathrm{JW} \mathrm{Jr}$ 1987. Virus-specific IgE and $\mathrm{IgG}_{4}$ antibodies in serum of children infected with respiratory syncytial virus. J Pediatr 110:87-90

4. Hanna CJ, Bach MK, Pare PD, Schellenberg RR 1981. Slow-reacting substances (leukotrienes) contract human airway and pulmonary vascular smooth muscle in vitro. Nature 290:343-344 
5. Marom Z, Shelhamer JH, Bach MK, Morton DR, Kaliner M 1982 Slowreacting substances, leukotrienes $C_{4}$ and $D_{4}$, increase the release of mucus from human airways in vitro. Am Rev Respir Dis 126:449-451

6. Weiss JW, Dragen JM, McFadden ER, Weller P, Corey EJ, Lewis RA, Austen KF 1983 Airway constriction in normal humans produced by inhalation of leukotrienes: potency, time course and effect of aspirin therapy. JAMA 249:2814-2817

7. Weller PR, Lee CW, Foster DW, Corey EJ, Austen KF, Lewis RB 1983 Generation and metabolism of 5 -lipoxygenase pathway leukotrienes by human eosinophils: predominant production of leukotriene $\mathrm{C}_{4}$. Proc Nat Acad Sci USA 80:7626-7630

8. Scott WA, Rouzer Ca, Cohn ZA 1983 Leukotriene $\mathrm{C}$ release by macrophages Fed Proc 42:129-133

9. Kaul A, Scott R, Gallagher MR, Scott M, Clement J, Ogra PL 1978 Respiratory syncytial virus infection: rapid diagnosis in children by use of indirect immunoflourescence. Am J Dis Child 132:1088-1090

10. Kay AB 1983 Mediators of hypersensitivity and inflammatory cells in the pathogenesis of bronchial asthma. Eur J Respir Dis (Suppl 129):1-44

11. Drazen JM, Austen KF, Lewis RA, Clark DA, Goto G, Marfat A, Corey EJ 1980 Comparative airway and vascular activities of leukotrienes $C_{4}$ and $D_{4}$ in vivo and in vitro. Proc Natl Acad Sci USA 77:4354-4358

12. Dahlen SE, Bjork S, Hedquist P, Arefors KE, Hammarstrom S, Lindgren SA Samuelsson B 1981 Leukotrienes promote plasma leakage and leukocyte adhesion in postcapillary venules in vivo: effects of relevance of acute inflammatory response. Proc Natl Acad Sci USA 78:3887-3891

13. Volovitz B, Faden H, Ogra PL 1988 Release of leukotriene $C_{4}$ in respiratory tract during acute viral infection. J Pediatr 112:218-222

14. MacGlashan DW, Schleimer RP, Peters SP, Schulman ES, Adams GR, Newball $\mathrm{HH}$, Lichtenstein LM 1982 Generation of leukotrienes by purified lung mast cells. J Clin Invest 70:747-751

15. Lewis RA, Soter NA, Diamond PT, Austen KF, Oates JA, Roberts LJ II 1982 Prostaglandin $\mathrm{D}_{2}$ generation after activation of rat and human mast cells with anti-IgE. J Immunol 129:1627-1631

16. Peters SP, MacGlashan DW Jr, Schulman Es, Schleimer RP, Hayes EC, Rocach J, Adkinson NF Jr., Lichtenstein LM 1984 Arachidonic acid metabolism in purified lung mast cells. J Immunol 132:1972-1979

17. Wohl MEB, Chernick V 1978 Bronchiolitis. Am Rev Respir Dis 118:759-781

18. Kaul TN, Welliver RC, Wong DT, Udwadia RA, Riddlesberger K, Ogra PL 1981 Secretory antibody response to repiratory syncytial virus infection. Am J Dis Child 135:1013-1016 